\title{
Investigating the industrial impact of hydraulic oil contamination on tool wear during machining and the development of a novel quantification methodology
}

\author{
Thawhid Khan $^{1}$ (D) - Matthew Broderick ${ }^{1} \cdot$ Chris M. Taylor $^{1}$ \\ Received: 1 September 2020 / Accepted: 5 November 2020 / Published online: 22 November 2020 \\ (C) The Author(s) 2020
}

\begin{abstract}
Water based metalworking fluids (MWFs) commonly used for cooling and lubrication during machining are utilised in combination with cutting tools, work materials, fixtures and machine tools. However, they are an often overlooked component of the overall machining process, despite the fact that in some reported cases MWF costs were twice that of tooling costs. During its life cycle in a machine tool, the MWF is exposed to changes due to a range of factors which impact its quality and longevity. The key process variables (KPVs) reviewed in this study are MWF concentration, hydraulic (tramp) oil, solid particulates, water quality, MWF pH and microbial contamination. The aim of the present work is to highlight these KPVs which impact machining quality and health and safety, and to present industrially applicable measurement, monitoring and control (MMC) methods and techniques. This review is supported by a machining case study which demonstrates the impact of a single KPV_hydraulic (tramp) oil on MWF quality and machining output, and the need for applying MMC methods. Continuous hydraulic (tramp) oil contamination into the cutting fluid can cause tool life and wear to vary by $70 \%$. A novel quantification methodology with gas chromatography was developed in this study to quantitatively measure hydraulic (tramp) oil contamination present within MWF and verified through experiments. The study overall highlights the need to apply a strict maintenance programme to increase the MWF lifetime and maintain performance for improved production, experimental process control and operator health and safety.
\end{abstract}

Keywords Metalworking $\cdot$ Metal cutting $\cdot$ Fluid $\cdot$ Coolant $\cdot$ Machining $\cdot$ Process $\cdot$ Variables

\section{Nomenclature}

GC Gas chromatography

KPV Key performance variables

MMC Measurement, monitoring and control

MWF Metalworking fluid

\section{Introduction}

Metalworking fluids (or MWFs), also referred to as cutting fluids or coolants interchangeably, are used in metal manufacturing

Thawhid Khan

thawhidkhan@yahoo.co.uk

1 The University of Sheffield Advanced Manufacturing Research Centre with Boeing, Advanced Manufacturing Park, Wallis Way, Catcliffe, Rotherham S60 5TZ, UK processes. F. W Taylor demonstrated the impact of using liquids during metal cutting [1]. By flooding the cutting zone with sufficient water, cutting speeds could be increased by 30 to $40 \%$ [2]. MWF usage encompasses both forming and cutting processes, this paper focusses on cutting applications. MWFs provide several benefits, such as thermal control during machining, improving the life and function of cutting tools, improving machinability of materials and preventing corrosion of machine tools [3]. The fundamental requirements of MWFs at the tool-chipworkpiece interfaces are removing heat produced by the cutting process, lubrication of contact faces to reduce friction and heat created between the workpiece and tool, and by transporting cut metal (known as swarf or chips) from the contact zone [4-7].

Typically, MWFs are used to improve the life and function of cutting tools, the machined surface quality, the machinability of materials and to prevent corrosion of machine tools. Generally MWFs consist of a base fluid and additive package(s) $[3,5,6,8]$. MWFs can be classified into the following categories $[6,9]$ : 
- Petroleum oil-containing fluids:

- Semisynthetic fluid;

- Straight oil.

- Emulsifiable oil (frequently referred to as "Soluble Oil");

- Synthetic nonpetroleum fluids:

- Straight synthetic oil.

- Solution synthetic fluid;

- Emulsion synthetic fluid;

With the cost for use and disposal of cutting fluids increasing combined with new stringent legislation, there is a focus on biodegradable and environmentally friendly cutting fluids. There is an increase in the development of vegetable-based cutting fluids which are less toxic and highly biodegradable [10-12].

Previous works $[10,13,14]$ have highlighted the relevance and significance of different additives regarding surface quality and tool wear. The addition of additive such as oil soluble extreme pressure (EP) additives such as phosphorous or sulphur as well as other novel additives can impact the life of the cutting tools when machining $[1,15]$. Advancements in the MWF additive technology has led to the development of several nanolubricants. These are lubricants which consist of a base oil with nanosized particles dispersed within. Analysis has shown the nanoparticles can easily penetrate into the cutting zone and be an effective method to reduce friction [16]. In the last decade, new alternatives to MWF's have been developed such as solid lubrication, minimum quantity lubrication and cryogenic cooling. MQL and dry machining are currently widely evaluated alternatives from a technical point of view [17].

Cutting fluids can be applied to the cutting zone with a variety of delivery methods [5]. Ensuring and maintaining the quality of the MWF influences its service life, which is important from a technological, environmental and economical perspective [3]. Approximately 2,000,000 $\mathrm{m}^{3}$ of cutting fluids are used per year in industry and can account for up to $15 \%$ of production costs. The purpose of MWFs is not widely recognised, they are often regarded as a supporting tool, necessary but not important [18-20]. Figure 1 demonstrates that in the production of a component, coolant technology can account for $15 \%$ of total manufacturing costs and the costs of MWFs were more than double the tool-related costs [21, 22].

This study highlights the key performance variables (KPVs) impacting the quality and lifecycle of MWFs. A number of measurement, monitoring and control (MMC) techniques will be discussed, which are currently used within industry to help maintain MWF quality. The novel aspect of this work is the inclusion of an industrial case study to analyse the

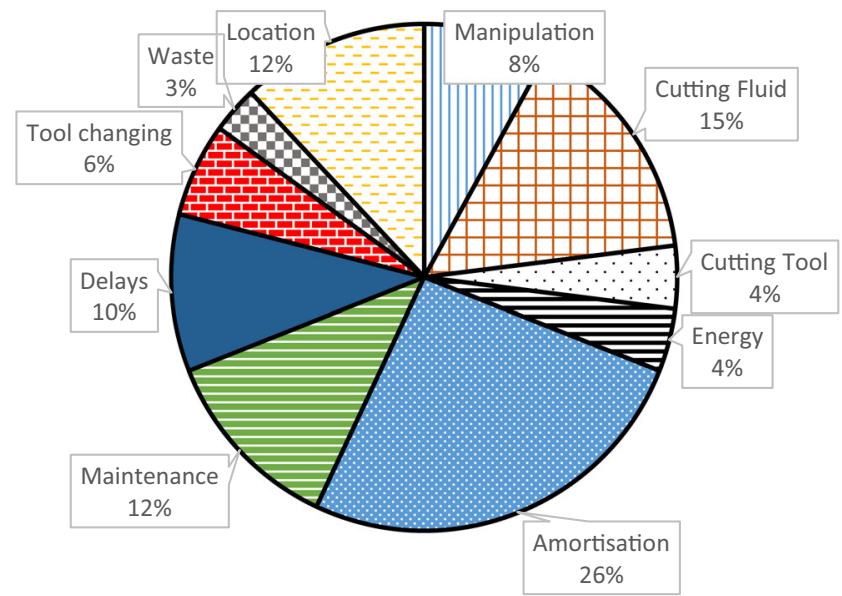

Fig. 1 Manufacturing cost in the German automotive industry [22]

impact of a single KPV-hydraulic oil and effectiveness of MMC methods on fluid maintenance and machining performance. The learning derived can help both practitioners and researchers in best practice MWF management and maintenance.

\section{Key process variables impacting fluid quality and longevity}

\subsection{Background to variables}

Regardless of the MWF type, some form of maintenance is required to maintain quality, performance and longevity. A number of factors can impact the performance of MWFs, with deteriorated properties influencing the loss of machining precision, reduced tool life, machine tool degradation and unpleasant working areas [23].

Rakic et al.'s [24] study stated that the main cause of failure of MWF systems (Fig. 2) are due to (1) contamination with particles; (2) corrosion; (3) increase of temperature; (4) decrease of machining accuracy due to tribological processes; and (5) other causes (e.g. flow and composition). Better fluid maintenance could reduce the occurrence of these failures.

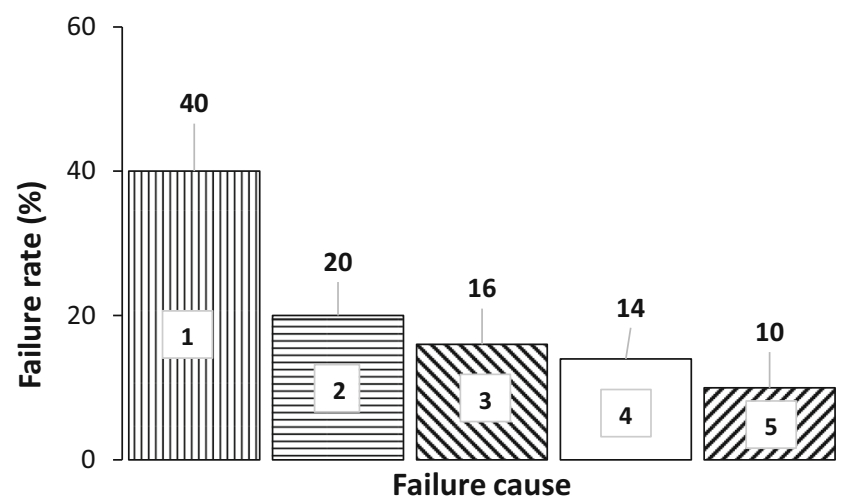

Fig. 2 Analysis of the cause of coolant system failure [24] 


\subsection{Key performance variables and the measurement, monitoring and control procedures}

After an initial literature review and consultation with experienced MWF practitioners, the KPVs selected for inclusion in this study are bulk fluid concentration, hydraulic (tramp) oil from machine lubricating oils, solid particulate contamination, water quality, fluid $\mathrm{pH}$ and microbial contamination. These variables can directly impact the quality of the MWF or influence the fluid's deterioration.

\subsubsection{Fluid concentration}

Fluid bulk concentration is a measure of the proportion of chemical components of a mixture diluted with water. MWFs are tailored to work within a specific concentration range, which is determined by the manufacturer for optimal performance to assure product quality and maximum cutting tool life, and for health and safety reasons. The minimum fluid concentration level must be observed to maintain the stability of the emulsion, $\mathrm{pH}$ level, good corrosion protection, biostability and cutting performance [5, 8]. High fluid concentrations can increase MWF costs due to wasted concentrate, reduction in heat dissipation, reduced lubrication, foaming, residue formation and more severe health risks such as dermatitis [5]. Increased concentration levels may indicate low fluid levels in the sump, a major cause is the evaporation and loss of water due to mist generation during machine use. In addition, MWF adhering to swarf is another mechanism for concentration change, depending on the type of material and generated surface area of the swarf as it is carried away via a conveyor system to a swarf container.

Measurement and monitoring The fluid level in the sump is a good visual indicator that the concentration needs checking. To maintain the target concentration, a refractometer is used for measurement. There are various types and styles available, ranging from basic handheld optical refractometers (Fig. 3) to more sophisticated digital units [8].

Control MWFs must be mixed in a certain way for the chemical components to be correctly dispersed. It is recommended that for any desired concentration of an oil in water emulsion, the concentrate is added to the water whilst it is stirred

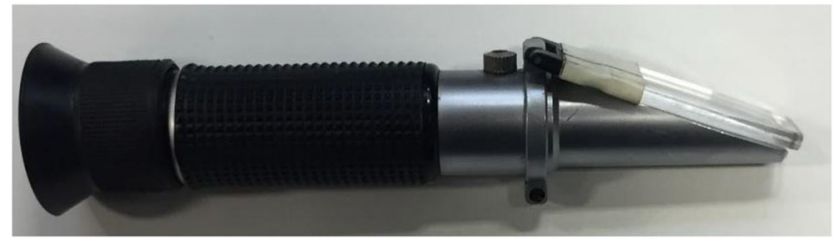

Fig. 3 Image of a typical hand refractometer used to measure fluid concentration vigorously. If this is not done correctly the emulsion may split [8], which is irreversible and requires a full fluid changeover. Adjusting concentration when necessary by moderate additions of emulsion or water will keep the MWF condition under control [25].

\subsubsection{Hydraulic (tramp) oil contamination}

Several different lubricants are used within machine tools to lubricate machine tool components and keep interacting metal surfaces apart. These oils can eventually end up in the coolant sump and contaminate the MWF causing multiple issues [8]. MWFs that contain emulsifiers in oil-based fluids can chemically emulsify the contaminating oils. The emulsifiers eventually become saturated; at this point, oil starts to float on the surface. Fully synthetic MWFs cannot mix and readily reject hydraulic (tramp) oil, also leading to oil floating on the surface.

High concentrations of hydraulic (tramp) oil in MWFs can lead to an increase in the level of oil mist and smoke formation because of the reduced cooling capability [5]. The increased risk of exposure to such aerosols makes the work environment less safe [8].

Measurement and monitoring Visual inspections of the machine sump give an indication of hydraulic (tramp) oil contamination as well as of the sump fluid level. As a rule of thumb, a full surface layer of oil indicates greater than $2 \%$ hydraulic (tramp) oil concentration relative to the total fluid, which would be detrimental to fluid life if left unattended. Hydraulic (tramp) oil levels should be kept to a minimum and inspected at least weekly [26].

Control Minimising interaction of hydraulic (tramp) oil and MWF is the best method of control, because the impact of their interactions is complex. Routine preventative maintenance should be carried out to prevent oil leaks from contaminating the fluid. Some hydraulic (tramp) oil contamination is inevitable due to MWF washing down the slideways during use and returning back into sumps. This will require removal. There are various methods of hydraulic (tramp) oil removal such as a simple disc and belt skimmer. Oil is collected on a material which has a greater affinity for oil than for aqueous emulsion, due to surface tension. The material used to collect the oil can be in the form of a continuous belt, rotating disc or a mop partially immersed in the fluid.

\subsubsection{Fine metallic particles}

All machining processes result in the creation of swarf (cut chips) of various sizes in the $\mathrm{mm}$ to $\mathrm{cm}$ range, and fines (solid particles or solid particulates) in the micron to submicron range. Particle composition is influenced by the cutting 
process, operating conditions, coolant characteristics and coolant systems [24]. The large surface area to volume ratio of these particles can catalyse other chemical or biological processes in the machine system [8].

Metal fines can make their way into the coolant pumps and be reintroduced into the cutting zone, which will contribute to tool wear as a third-body abrasive mechanism, resulting in reduced tool life and poor surface finish. These fines can eventually settle out of the fluid and combine with hydraulic (tramp) oil to produce a sludge which can float on the surface of the bulk fluid as well as depositing around the sump, creating suitable conditions for undesirable anaerobic bacterial growth $[8,24,27]$.

Measurement and monitoring Techniques such as optical microscopy allow fine contaminating particles to be counted manually. Automated optical particle counters are less labour intensive. Laser-based instruments use an unimpeded laser beam which is interrupted when a particle passes through the instrument [28].

Control A number of options exist to separate fine particles from MWFs, such as magnetic separators, filters and weirs [25] and centrifuges.

Centrifuges are extremely effective in removing all types of solid fines from a liquid medium. They are mechanical devices with moving parts that rotate at high speeds, separating the solid material from a liquid through centrifugal forces. These units consist of a horizontal revolving bowl, inside which a screw rotates in the same direction. The fluid enters the centre of the bowl, and the solids are transferred to the outer edge. Centrifuges are also capable of removing hydraulic (tramp) oil from water-mix MWFs. Hydrocyclones work on the same principle for separation, however the fluid spins rather than a bowl being spun [25]. Two-stage hydrocyclone treatments can trap particles down to about $5 \mu \mathrm{m}[23,25]$.

\subsubsection{Water quality}

Suitable water quality is important when preparing the MWF emulsion or solution, to ensure long term stability and performance. Hardness values must be compared to manufacturer's requirements [27]. Water hardness is essentially a measure of the dissolved minerals within the water solution [29]. The interactions of dissolved metallic ions in water with emulsifiers may reduce the stability of the emulsion, resulting in the oil and water phases splitting.

Water can be classified as soft or hard [30]. The water hardness for diluting MWFs should be in the range from 80 to $125 \mathrm{ppm}$ as per Table 1 . Outside of this range, excessively soft water mixtures cause foaming [31]. Excessively hard water can cause chemical instability and emulsion splitting, alongside combining with emulsifiers of synthetic or
Table 1 Water hardness classification [30]

\begin{tabular}{ll}
\hline $\mathrm{CaCO}_{3}(\mathrm{ppm})$ & Classification \\
\hline Less than 50 & Very soft water \\
50 to 120 & Soft water \\
120 to 240 & Medium hard water \\
240 to 360 & Hard water \\
More than 360 & Very hard water \\
\hline
\end{tabular}

semisynthetic concentrates to form scum deposits inside pipes or machine tools $[5,8]$.

Measurement and monitoring The units of water hardness are ppm, where 1-ppm hardness is defined as $1 \mathrm{mg} / \mathrm{L}$ of $\mathrm{CaCO}_{3}$. Test strips are available for quick and easy determination. The strips are dipped in the water used to make up the coolant and colour changes reflect the water hardness, usually evaluated with a reference colour chart [32].

Control Good quality water is essential for mixing MWF concentrates. Water treatments may be required to achieve this and there are a number of options, for instance reverse osmosis or deionising the water. This can greatly enhance the fluid life expectancy due to absence of dissolved minerals which enhance fungal growth $[5,8]$.

\subsubsection{MWF pH}

Once water based MWFs are diluted, the $\mathrm{pH}$ is typically between 8.5 and 9.5. The MWF formulation acts as a buffer solution which maintains this $\mathrm{pH}$ level, preventing bacterial growth. A high $\mathrm{pH}$ leads to health and safety issues for the operator such as skin irritation and occupational dermatitis [33].

Measurement and monitoring $\mathrm{pH}$ indicator strips (Fig. 4b) can be applied to MWFs in the sump. MWF pH should be maintained within the suppliers recommended range [27]. At $\mathrm{pH}<8.5$, bacterial growth rates increase rapidly and when $\mathrm{pH}$
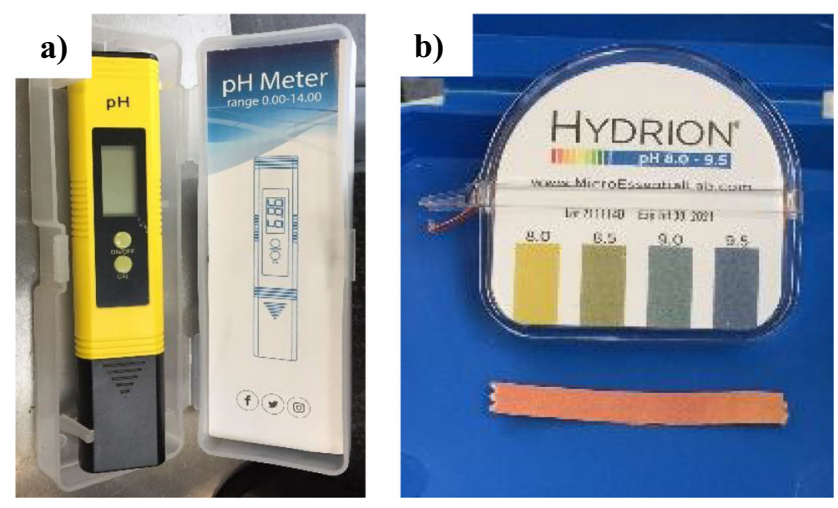

Fig. $4 \mathrm{pH}$ can be determined using a a portable meter or $\mathbf{b}$ litmus strips 
$<7.5$ carbon steel may rust. A pH above 9.5 must also be avoided due to skin reaction [34]. The use of a dedicated digital $\mathrm{pH}$ probe or meter (Fig. 4a) allows real time measurements and monitoring.

Control Specific additives such as buffering agents can be used to maintain the MWF and increase its lifetime, by restoring $\mathrm{pH}$ to its required value. If the $\mathrm{pH}$ cannot be restored by this method, the alternative solution is a full fluid change.

\subsubsection{Microbial contamination}

A major cause of fluid spoilage is microbial contamination [5]. Water miscible MWFs are commonly associated with microbial degradation, which leads to functional and hygienic concerns [35]. The presence of water combined with MWF constituents create suitable conditions for microorganisms to grow. A single MWF can be composed of up to sixty different components which are a source of nutrients and energy for microorganisms $[4,35]$. Bacteria can gradually metabolise these components [3].

The impact on machine operator health must also be highlighted. In their supplied condition, MWFs can be hazardous to health, especially when biocides are used. Once microbes are present, interaction with the skin and lungs can result in dermatitis, occupational asthma, extrinsic allergic alveolitis, and other breathing problems $[3,36]$. When considering the combination of bacteria, fungi, modified additive chemicals and fine debris, the interactions may lead to unknown health risks [3].

Measurement and monitoring As described, good fluid management includes the control of MWF concentration and $\mathrm{pH}$, both of which can impact bacterial formation [25]. Dip slides are used as a cost effective means of testing the microbial content of liquids. The dip slide carries a sterile culture medium. The UK Health and Safety Executive (HSE) recommends the use of dip slides to monitor the general activity of aerobic

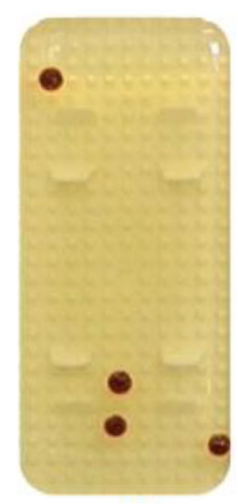

$<10^{3}$

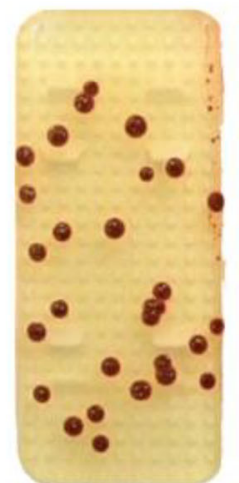

$10^{3}$

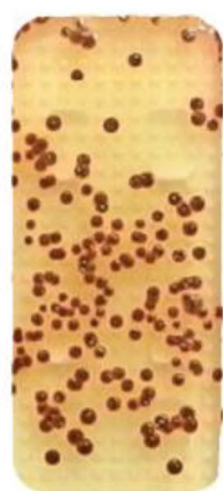

$10^{4}$

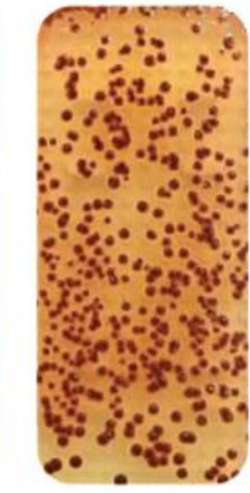

$10^{5}$ bacteria [37]. If bacteria are present in the coolant, colonies should form on the dipstick as shown in Fig. 5 [27].

Other techniques such as the catalase test, 2-h oxygen demand, and the ATP molecule detection test can provide more immediate data on the level of microbes in a system [38].

Control Biocides can be used to control bacterial and fungal growth. Most water-mix MWFs contain a biocide within the mixture, whilst others rely on the natural resistance of the components to microbiological consumption. Biocides can be used in a number of ways, either preventatively when supplied with the additive package of the cutting fluid or reactively to tackle an already contaminated fluid [3]. Selvaraju et al. [39] found that the concentration and type of biocide had a significant influence on effectiveness. Overuse of biocides can have a harmful impact on industrial workers due to their toxic properties [34]. Biocides must be used within practical limits [3].

Alternative methods for eliminating bacteria include exposure to ultraviolet (UV) radiation and ultrasonic sound [3, 40, 41].

This study will investigate the industrial impact of a single KPV - hydraulic (tramp) oil contamination during machining and its impact on performance. It will utilise gas chromatography to develop a novel chemical analysis methodology to quantify hydraulic (tramp) oil presence in the cutting fluid used during machining.

\section{Experimental work}

\subsection{Trial configuration}

Milling in this project was carried out using two 3 -axis vertical $\mathrm{CNC}$ machines using a setup demonstrated in Fig. 6. Machining involved a simple shoulder milling process of numerous aerospace alloys using coated cutting inserts. Surface speeds were dependent on the work piece

Fig. 5 Bacterial growth on dip slides - low to high bacterial presence [27]

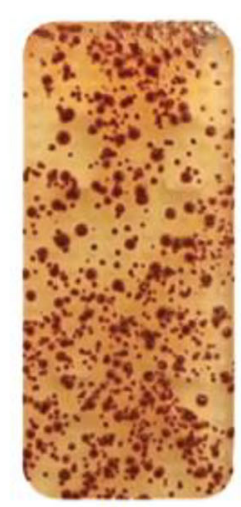

$10^{6}$

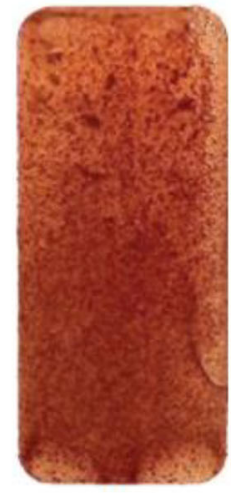

$10^{7}$ 


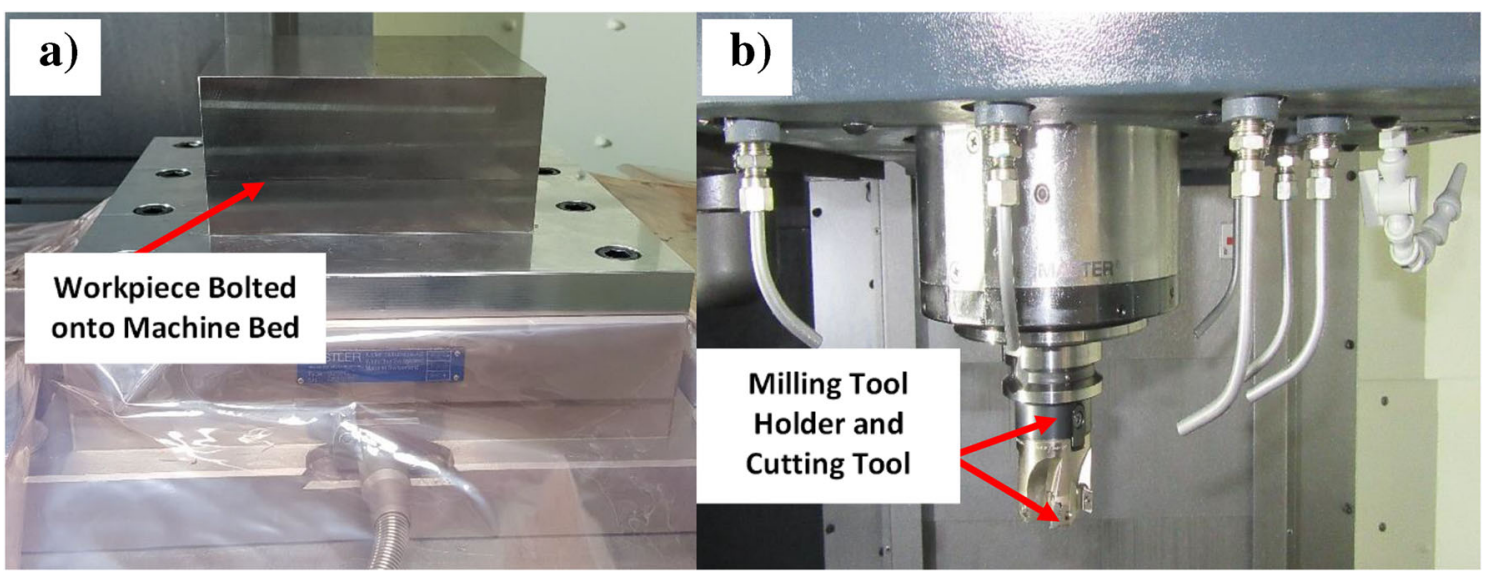

Fig. 6 Experimental set-up of milling process: a Workpiece setup on machine bed; b Tool holder and cutting tool in the machine spindle

machined. The tool performed a straight line cut through the work material, following common practice the tool entered the cutting pass in an arc to control chip form and forces on entry.

Machine A is a state-of-the-art industrial 3-axis CNC milling platform with a medium-sized sump (550 L) was used for cutting fluid trials. The lubricating oil used for the machine tool A slideways and box-ways contaminated the MWF in the sump. Large amounts of hydraulic (tramp) oil were observed in the sump and filtration chambers. According to the manufacturer (and verified by testing), the contamination rate of slideway grade 68 oil for a $6-\mathrm{h}$ machining time in an 8-h period was $259 \mathrm{~mL}$.

Machine B which is an older model with a different slideway design and has a low lubrication oil output compared to machine A. According to the manufacturer and verified by testing, the dosage rates of slideway grade 68 oil in machine $\mathrm{B}$ were between 5.8 and 14.5 times less than machine A. The reason being that the oil dispense rate of machine $\mathrm{B}$ whilst powered on was constant, whether machining or not.

\subsection{Tool life testing}

Numerous tool wear measurements are taken after machining for set time intervals until a failure limit is reached. Tool life is calculated from the machining time taken to reach this failure limit. The cutting tool is removed from the machine and inspected using an ISM-PM200 digital microscope. Tool wear is initially analysed after a set machining time period, if the average wear is below or above a set wear threshold at this point, the machining time interval is adjusted to ensure the moment of failure is captured. The digital microscope fixed to a stand was used for measuring flank wear on the cutting tool inserts as shown in Fig. 7a. The device was calibrated against a glass etched measuring scale. Wear was measured after a complete length of cut with the given cutting parameters. Tool wear was measured on the flank face of the cutting edge, focusing on the corner radius (CR) feature of the tooling insert. Previous work dictated that this region was in cutting contact and would wear out in the shortest time and was therefore the area of interest. Images were repeatedly taken until
Fig. 7 a USB (ISM-PM200) digital microscope set up to take cutting insert flank wear images, b example of where five tool wear measurements were taken on the flank face of the cutting region of the insert

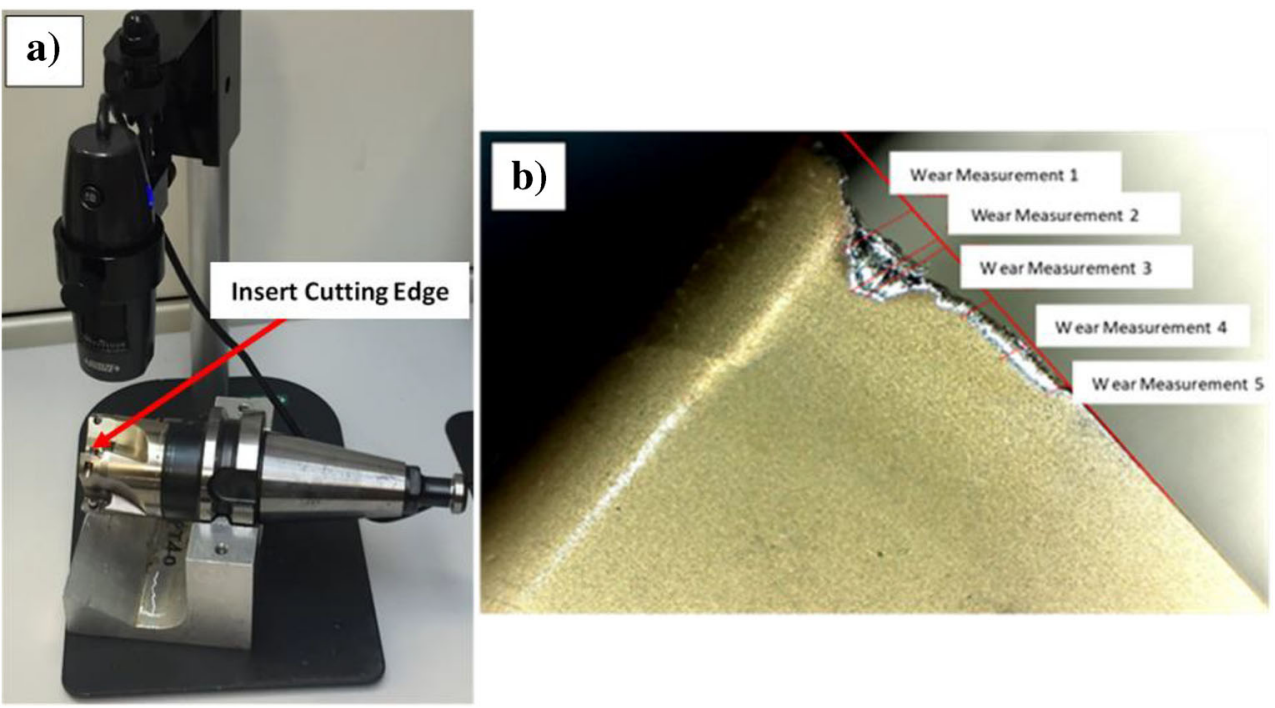




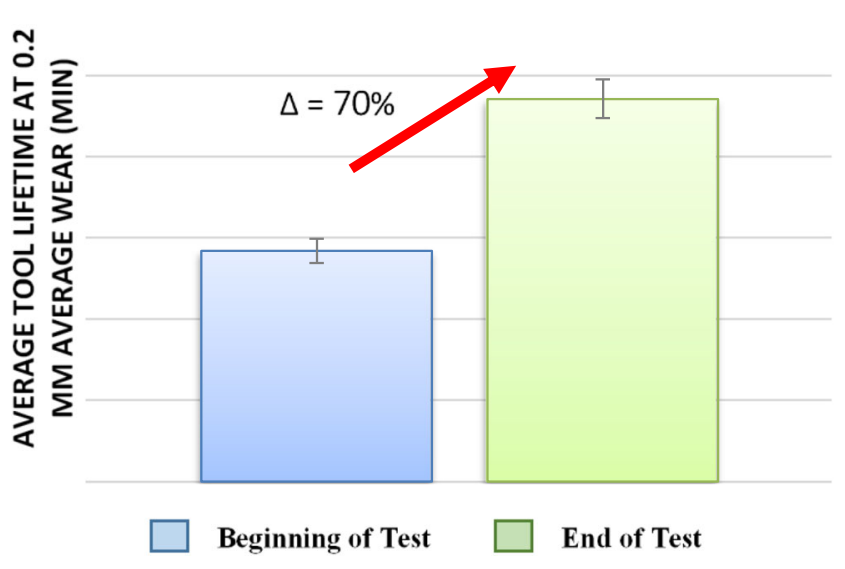

Fig. 8 Change in tool life due to tramp oil contamination. Error bars represent $99 \%$ confidence interval

tool failure (average measured wear $>0.2 \mathrm{~mm}$ ). Five measurements were taken at different time intervals per tooling insert as shown in Fig. $7 b$.

\subsection{Chemical analysis technique for hydraulic (tramp) oil quantification}

Gas chromatography (GC) was employed to look at the different components of several reference samples that could be vaporised without decomposition. This was done to examine key features in the responding chromatograms, and calibrate peak heights with concentration to be able to quantify the levels of oil in the MWF samples. GC is a separation technique capable of separating complex mixtures based primarily upon differences of boiling point, of vapour pressure and of polarity. Gas chromatography utilizes an inert gaseous mobile phase and a liquid stationary phase. The mobile phase, which is the carrier gas, transports the sample to be tested onto a column enclosed in a temperature-controlled oven. As the sample passes through the column, chromatographic separation occurs, and the separated components are analysed by a

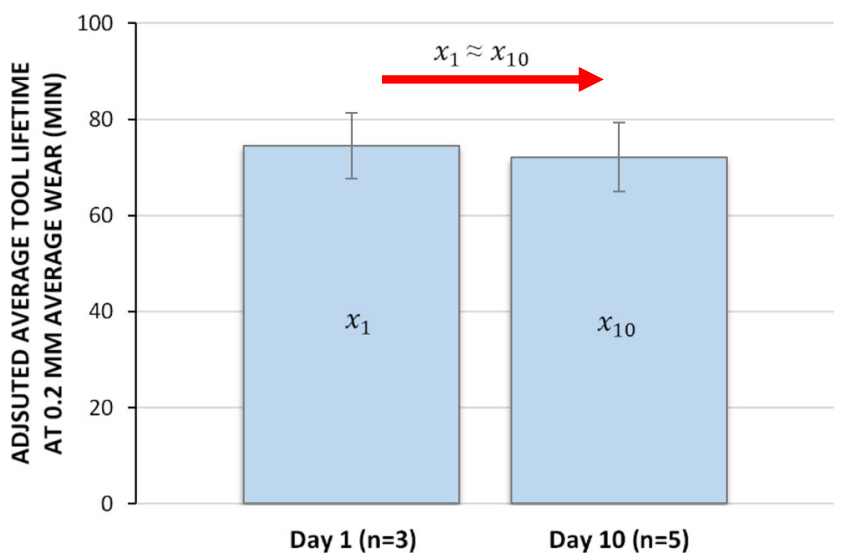

Fig. 9 Adjusted tool life results at the beginning and end of testing over 10 days with the application of separation tank modifications and the IFDR system on machine A. Error bars represent $99 \%$ confidence interval detector. The detector provides an electronic signal proportional to the amount of eluting analytes [42].

\section{Results and discussion}

This metal machining case study was carried out to investigate the real application impact of a single KPV and MMC methods on the condition and quality of MWF. It investigated the impact of contaminating hydraulic (tramp) oil on tool life during machining and explored the ability of a filtration system to maintain contaminating oil at a minimum level. This process also involved the development of a novel quantification methodology to measure hydraulic (tramp) oil contamination present, to support the tool life data produced, highlighting the impact of the different levels of tramp oil present in the MWF during machining trials.

This case study aimed to (a) identify the impact of a single KPV, hydraulic (tramp) oil, on the repeatability of machining experiments, and (b) determine the effectiveness of potential control measures that could be applied. Machinability trials were being carried out on commercial emulsion MWFs so that their performance could be quantified and compared.

\subsection{Tool life testing}

\subsubsection{Background}

During machining trials using machine $\mathrm{A}$, a continuous dose of hydraulic (tramp) oil entered and contaminated the MWF, the contamination rate of slideway grade 68 oil for a 6-h machining time in an 8-h period was 259 $\mathrm{mL}$. Note that the capacity of the lubricating tank was just over $4 \mathrm{~L}$. The results demonstrated that hydraulic (tramp) oil contamination caused the MWF performance to vary as measured through tool life consistency. In the most extreme case, tool life increased by almost $70 \%$ over time (Fig 8) as a result of hydraulic (tramp) oil build-up in the fluid system. Similar behaviour trends were observed by Popov et al. [43] where with increasing levels of hydraulic oil contamination led to tool life increasing by almost $40 \%$, before a decrease was observed at high levels of contamination. The increase in tool life can be expected due to the presence of antiwear and extreme pressure additives in the hydraulic oil. Most antiwear additives contain zinc dithiophosphate, whereas extreme pressure additives contain sulphur and phosphorous compounds. These compounds are usually activated by metal-on-metal contact and high loads, causing them to interact with the metal surface and form a protective sacrificial film. The increasing presence of sulphur and phosphorous compounds within the MWF with higher hydraulic (tramp 


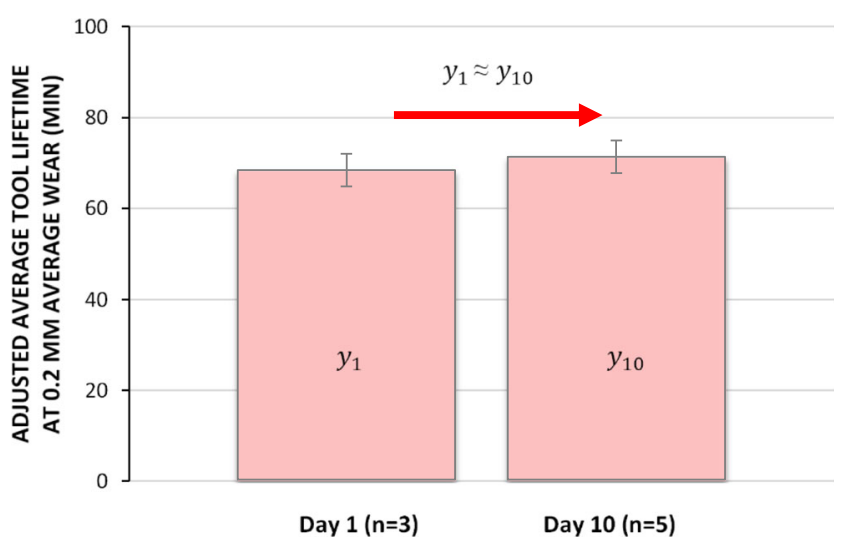

Fig. 10 Adjusted tool life results at the beginning and end of testing over 10 days using a low oil dosing control platform on machine B. Error bars represent $99 \%$ confidence interval

oil) contamination levels may be responsible for the extended tool life due to better antiwear and lubricating properties [15, 44-47]. Popov et al. [43] observed tool life reach a steady state before beginning to decline which is a common trend with increasing levels of contamination because of the decreasing cooling effect of the fluid [46].

\subsubsection{Application of control}

To determine the effectiveness and impact of MMC equipment on limiting and maintaining low levels of hydraulic (tramp) oil, machine A was subsequently adapted to improve control. (1) An oil-coolant separation tank which was causing 90 to $95 \%$ of the collected contaminating oil and MWF from under the machine slideways to enter back into the sump was removed, and (2) an IFDR300 filtration system was retrofitted, this was a hydrocyclone and tramp oil separator as described in Section 2.2.2 and Section 2.2.3, respectively. Machining tests were done over a period of two working weeks, where repeat tool life tests were performed on the nominal first (day 1) and last working day (day 10) of that period. Meanwhile the MWF was kept in the machine, monitored and controlled twice daily, and allowed to be used passively, i.e. in general machining use between days 1 and 10. Results for the adapted machine A are shown in Fig. 9. Data on the ordinate axis has been adjusted to a scale from 0 to $100 \mathrm{~min}$, and $n$ represents the number of repeat tool life tests that were carried out. Tool life was consistent over the 10-day testing period ( $x_{1} \approx x_{10}$ minutes), indicating that the MMC procedures implemented were effective.

To further verify the tool life results achieved after control was implemented to machine $\mathrm{A}$, machine $\mathrm{B}$ which was an older model with a different slideway design, was used as a baseline for low lubrication oil output to compare against machine A. According to the manufacturer and verified by testing, the dosage rates of slideway grade 68 oil in machine $\mathrm{B}$ were between 5.8 and 14.5 times less than machine A. The MWF supply flow rates for each machine were very similar. The same MWF type was used, along with the same water source, work materials, tool types, and machining parameters. The results (Fig. 10) show that the initial tool life ( $y_{1}$ minutes) was almost identical to results from the last day of testing $\left(y_{10}\right.$ minutes).

Figure 11 compares the tool life results at the beginning and end of testing across the two platforms (machines $\mathrm{A}$ and $\mathrm{B}$ ), highlighting that the four results are the same within the intervals of confidence. The results for machine A demonstrated consistent performance and therefore experimental control over the period of two working weeks, and matched the low lubrication rate machine B. These tests demonstrate that high levels of hydraulic (tramp) oil cause variation (up to 70\%) in machining performance regarding tool life. The contaminating lubricating oil from machine slideways has been stated in several studies $[48,49]$ as being beneficial for machinability due to it enriching the MWF and influencing machining properties encouraging better antiwear properties as explained earlier. However, in the context of a repeatable experiment the influence of hydraulic (tramp) oil on tool wear behaviour was undesirable and in the long-term will lead to the degradation of the cutting fluid's properties, thus highlighting the need to control this KPV [43].
Fig. 11 Comparison of adjusted tool lives across machine A (blue) and machine B (red) at the beginning and end of testing. Error bars represent $99 \%$ confidence level

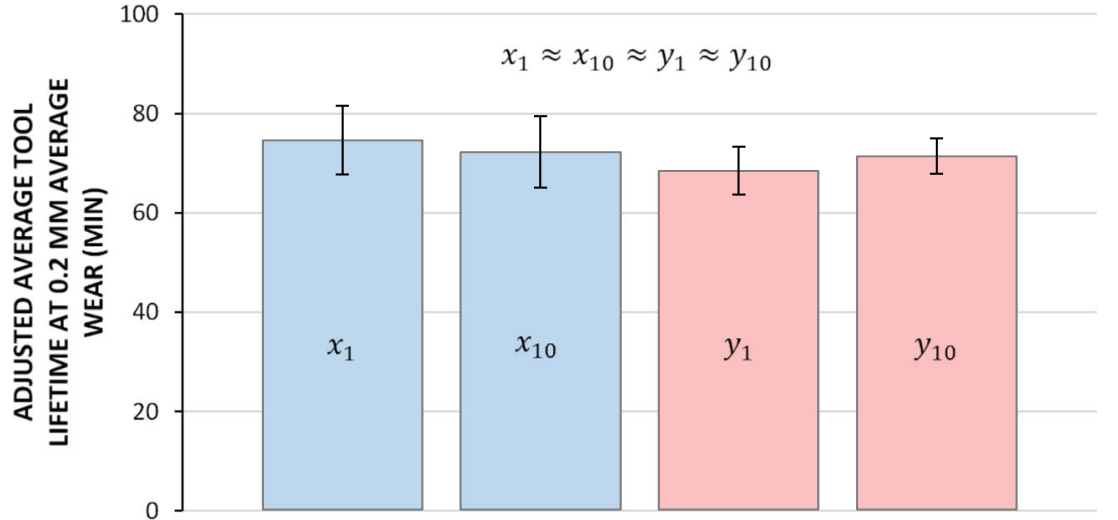


Table 2 Samples analysed by gas chromatography to quantify hydraulic (tramp) oil contamination

\begin{tabular}{lll}
\hline Sample ID & Sample description & Sample notes \\
\hline A & Neat MWF & MWF concentrate \\
B & Neat G68 oil & Lubricating oil (contaminate) \\
C & Emulsion & 8\% of A in $\mathrm{H}_{2} \mathrm{O}$ mains water) \\
$\# 1$ & Tested emulsion sample & Before machine adaptation \\
$\# 2$ & Tested emulsion sample & After machine adaptation (day 1) \\
$\# 3$ & Tested emulsion sample & After machine adaptation (day 10) \\
\hline
\end{tabular}

\subsection{MWF chemical analysis for hydraulic (tramp) oil measurement}

This study aimed to develop a chemical analysis methodology which would give a quantifiable measurement of hydraulic (tramp) oil present in MWF compared to existing measuring and monitoring techniques. Current measurement techniques involve allowing the hydraulic (tramp) oil contaminated cutting fluid to stand until the oil settles at the top surface of the solution, at which point the contamination percentage is estimated [43]. Having a quantifiable method would allow the study to directly link the tool life behaviour observed in Section 4.1.2 to the hydraulic (tramp) oil levels in the cutting fluid. It would also allow a further check that the control measures applied to machine A to control hydraulic (tramp) oil were effective.

Chemical analysis using GC was conducted on MWF samples from three points in time for machine A. These were (\#1) when tool life had increased to a maximum level, before the IFDR system was implemented and the separation tank was modified and; (\#2) at the beginning $\left(x_{1}\right)$ and; (\#3) end $\left(x_{10}\right)$ of test periods where tool life was seen to have been maintained constant (Fig. 9).
With this technique and using a sample of the virgin contaminant (G68 lubricating oil), a gradient calibration curve was formed using samples with known levels of contamination. From calibration an equation was derived, based on which any future analysis would simply require integration of one peak to give the value of contamination. Using GC, three reference samples and three MWF test samples (Table 2) were analysed. The MWF test samples \#1 to \#3 were collected as explained above. The reference samples comprised of (sample A) neat MWF, (sample B) neat contaminating oil G68 as used to lubricate machine A's slideways, and (sample C) an unused MWF emulsion composed of sample A (at 8\%) in mains water as a comparative, controlled sample.

\subsubsection{Chemical analysis results}

The reference samples were analysed by GC where characteristic signals were identified from the chromatograms. A small peak around 12.1-min retention time that was only present in the contaminant (sample B) was detected (Fig. 12a), so this was the signal used for calibration of the contaminant. It should be noted that this signal was weak, which might cause issues with sensitivity and detection limits. The calibration for contaminant levels was achieved by testing various concentrations of contaminant, sample B in emulsion C, and analysing the peak height in GC at $12.1 \mathrm{~min}$. Each of these samples were analysed by GC in triplicate using tetrahydrofuran (THF) as the carrier solvent. A calibration curve against weight/volume $(\% \mathrm{w} / \mathrm{v})$ values (Fig. 12b) was achieved with a linearity coefficient $R^{2}$ of 0.9982 .
Fig. 12 a Overlay of GC response with varying concentrations of contamination in emulsion $\mathrm{C}$, at 12.1-min retention time $\mathbf{b}$ derived calibration curve from peak heights at 12.1-min retention time

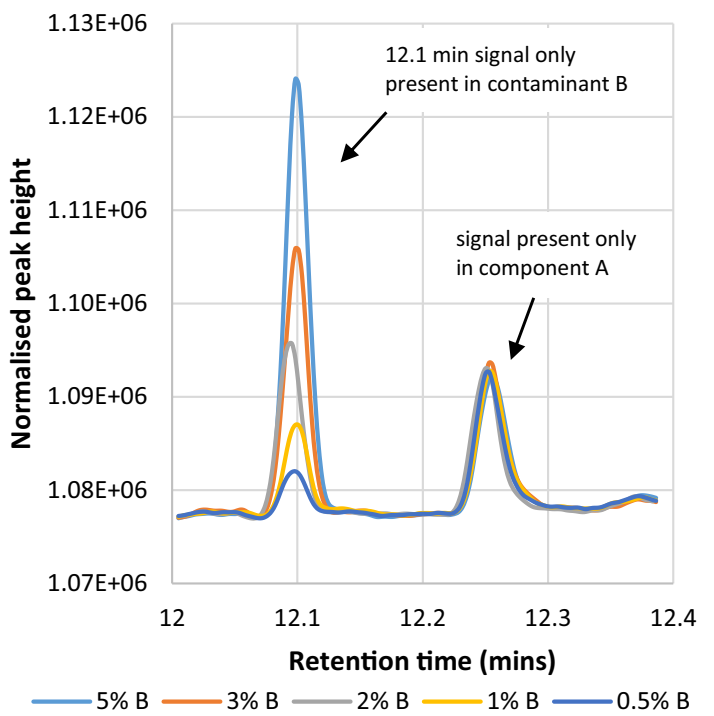

a)

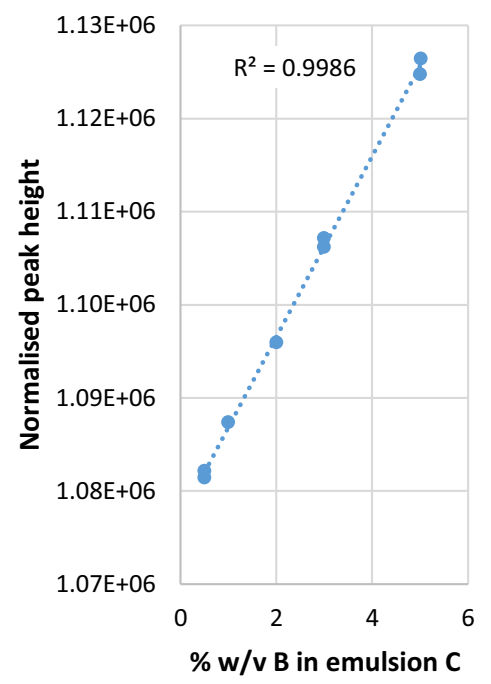

b) 
Table 3 Results of the GC analysis of the unknown emulsion test samples. Note that values with an asterisk $(*)$ were results which may be below the limit of detection so should be treated as such

\begin{tabular}{ll} 
Sample ID & $\begin{array}{l}\text { Average \% } \mathrm{B} / \mathrm{v} \\
\text { in emulsion }\end{array}$ \\
\hline$\# 1$ & $0.43 \%$ \\
$\# 2$ & $<0.10 \% \%^{*}$ \\
$\# 3$ & $<0.14 \%^{*}$ \\
\hline
\end{tabular}

Using the calibration curve Fig. 12b, the GC analysis of the MWF test samples (\#1 to \#3) focused on the peaks generated at $12.1 \mathrm{~min}$ and the heights measured. Thereby the concentration of contaminating oil was quantified. Results are supplied in Table 3.

The GC results in Table 3 show that before controls were applied there was a high level of oil contamination in the MWF as seen with Sample \#1. However, with the removal of the separation tank and the installation of the IFDR system, the contaminating levels of G68 were reduced (Sample \#2) and maintained low as shown by the GC results for Sample \#3. These results show a direct correlation between tool life and hydraulic (tramp) oil levels. They demonstrate that high input rates of lubrication oil make tool life unpredictable, whereas when control measures were applied and hydraulic (tramp) oil levels were minimal, tool life behaviour was consistent. This GC analysis method provides an accurate methodology in comparison to current industry techniques which typically involve visual inspection and estimation of oil levels present [26].

\section{Conclusions}

The aim of this research was to highlight key performance variables (KPVs) influencing the quality and condition of metalworking fluids (MWFs) and the measurement, monitoring and control methods applied to maintain them. This was supported by a case study which experimentally demonstrated the impact of a selected KPV during machining.

The key conclusions drawn from the work are as follows:

1. Uncontrolled leakage of machine lubricating oil into the MWF is believed to have caused an observed improvement of the MWF performance in terms of cutting tool wear characteristics (up to $70 \%$ ) over time. The application of MMC systems effectively controlled this behaviour.
2. Gas chromatography showed promise as a viable technique to detect and quantify lubricating oil contamination in MWFs. Before machine modifications, $0.43 \%$ lubricating oil was contaminating the MWF, whereas after modifications the measurement dropped to below $0.15 \%$. Further improvements in detecting low levels of lubrication oil presence could be pursued.

Acknowledgments The authors would like to thank the Rolls-Royce for their support of the case study, also the UK Lubricants Association Product Stewardship Safety Group for their permissions to reproduce Fig 2.4 from the recent Good Practice Guide. Finally, the authors would like to thank Farapack Polymers Ltd. for their services towards the development of a gas chromatography analysis methodology.

Funding The authors would like to thank the Department of Business Energy and Industrial Strategy, Innovate UK, UK HVM Catapult and the Aerospace Technology Institute for funding this research via the Manufacturing Portfolio programme (ref 113081).

Open Access This article is licensed under a Creative Commons Attribution 4.0 International License, which permits use, sharing, adaptation, distribution and reproduction in any medium or format, as long as you give appropriate credit to the original author(s) and the source, provide a link to the Creative Commons licence, and indicate if changes were made. The images or other third party material in this article are included in the article's Creative Commons licence, unless indicated otherwise in a credit line to the material. If material is not included in the article's Creative Commons licence and your intended use is not permitted by statutory regulation or exceeds the permitted use, you will need to obtain permission directly from the copyright holder. To view a copy of this licence, visit http://creativecommons.org/licenses/by/4.0/.

\section{References}

1. Grzesik W (2008) Chapter ten - cutting fluids. In: Grzesik W (ed) Advanced Machining Processes of Metallic Materials. Elsevier, Amsterdam, pp 141-148

2. Institute of Advanced Manufacturing Sciences, Incorporated Machining Xcellence Division (1995) Pollution prevention guide to using metal removal fluids in machining operations. I.o.A.M. Sciences, Cincinnati. http://www.coolantmaintenance.com/ techpapers pdf/greenfluids manual.PDF

3. Madanchi N, Thiede S, Herrmann C (2017) Functional and environmental evaluation of alternative disinfection methods for cutting fluids. Procedia CIRP 61:558-563

4. Koch T, Passman F, Rabenstein A (2015) Comparative study of microbiological monitoring of water-miscible metalworking fluids. Int Biodeterior Biodegradation 98:19-25

5. Center IWR (2003) Cutting fluid management: small machining operations. Available from: https://scholarworks.uni.edu/cgi/ view content.cgi article $=1005 \&$ context $=$ iwrc_facbook. Accessed Dec 2018

6. ASTM international (2019) ASTM D2881-19 - Standard classification for metalworking fluids and related materials. Pennsylvania, p 3. https://www.astm.org/Standards/D2881.htm. Accessed July 2020 
7. ASTM international (2018) E2523 - 13: Standard terminology for metal working fluids and operations. Pennsylvania, p 7. https:// www.astm.org/Standards/E2523.htm. Accessed July 2020

8. Reynolds B, Fecher D (2012) Metalworking fluid management and best practices. [cited 2018; Available from: https://www. productionmachining.com/articles/metalworking-fluidmanagement-and-best-bractices. Accessed June 2020

9. Byers J (ed) (2018) Metalworking fluids. CRC Press, Boca Raton. https://doi.org/10.4324/9781351228213

10. Debnath S, Reddy MM, Yi QS (2014) Environmental friendly cutting fluids and cooling techniques in machining: a review. J Clean Prod 83:33-47

11. Kuram E, Ozcelik B, Bayramoglu M, Demirbas E, Simsek BT (2013) Optimization of cutting fluids and cutting parameters during end milling by using D-optimal design of experiments. J Clean Prod 42:159-166

12. Tschätsch H, Reichelt A (2009) Cutting fluids (coolants and lubricants). In: Applied Machining Technology. Springer, Heidelberg, $p$ 349-352. https://doi.org/10.1007/978-3-642-01007-1 21

13. Yan P, Rong Y, Wang G (2016) The effect of cutting fluids applied in metal cutting process. Proc Inst Mech Eng B J Eng Manuf 230(1):19-37. https://doi.org/10.1177/0954405415590993

14. Khajehzadeh M, Boostanipour O, Amiri S, Razfar MR (2020) The influence of ultrasonic elliptical vibration amplitude on cutting tool flank wear. Proc Inst Mech Eng B J Eng Manuf 234(12):14991512. https://doi.org/10.1177/0954405420929782

15. Brinksmeier E, Meyer D, Huesmann-Cordes AG, Herrmann C (2015) Metalworking fluids-mechanisms and performance. CIRP Ann 64(2):605-628

16. Sayuti M, Sarhan AA, Salem F (2014) Novel uses of SiO2 nanolubrication system in hard turning process of hardened steel AISI4140 for less tool wear, surface roughness and oil consumption. J Clean Prod 67:265-276

17. Benedicto E, Carou D, Rubio E (2017) Technical, economic and environmental review of the lubrication/cooling systems used in machining processes. Procedia Eng 184:99-116

18. Graham D (2000) Dry out. Cutting Tool Eng 52:1-8. https://www. ctemag.com/news/articles

19. Astakhov VP (2006) Tribology of metal cutting. Tribology and Interface Engineering Series, No.52. Elsevier Science, Amsterdam

20. de Moraes DL, Garcia MV, Lopes JC, Ribeiro FSF, de Angelo Sanchez LE, Foschini CR, de Mello HJ, Aguiar PR, Bianchi EC (2019) Performance of SAE 52100 steel grinding using MQL technique with pure and diluted oil. Int J Adv Manuf Technol 105(10): 4211-4223

21. Brinksmeier E, Walter A, Janssen R, Diersen P (1999) Aspects of cooling lubrication reduction in machining advanced materials. Proc Inst Mech Eng B J Eng Manuf 213(8):769-778. https://doi. org/10.1243/0954405991517209

22. Elahi F, Nisha ZA, Ferdous I-U (2015) Intelligent cooling system for machining. Conference: 3rd International Conference on Mechanial Engineering \& Renewable Energy, Chittagong, vol 3. https://doi.org/10.13140/RG.2.1.3452.5521

23. Sutherland K (2008) Machinery and processing: managing cutting fluids used in metal working. Filtr Sep 45(7):20-23

24. Rakić R, Rakić Z (2002) The influence of the metal working fluids on machine tool failures. Wear 252(5):438-444

25. Neadle D (2010) Control and maintenance of metalworking fluids. Lube Magazine 73:1. http://www.lube-media.com/wpcontent/uploads/2017/11/Lube-Tech073-Controland maintenanceofmetalworkingfluids.pdf. Accessed Dec 2019

26. QCare - Technical services and support for metalworking fluids \& industrial lubricants. Oils Q (ed). Q8. https://login.q8oils.co.uk/ Portals/60/QCare_17.07.18.compressed.pdf
27. (2018) Good practice guide for safe handling and disposal of metalworking fluids. U.K.L.A.U.H.a.S.E. (HSE) (ed). United Kingdom Lubricants Association (UKLA). http://www.ukla.org.uk/wpcontent/uploads/UKLA-HSE-Good-Practice-Guide-for-SafeHandling-and-Disposal-of-Metalworking-Fluids.pdf. Accessed June 2020

28. Corporation N Particle counting - oil analysis 101. Machinery Lubrication [cited 2019 March]; Available from: https://www. machinerylubrication.com/Read/353/particle-counting-oilanalysis. Accessed Jan 2019

29. (2009) Coolant, or metalworking fluid measurement \& control [cited 2018; Available from: http:/www.coolantmaintenance.com/ coolant science/coolant measurement control.htm. Accessed Dec 2018

30. Aquadur Aquadur Sensitive Test Strips[cited 2018; Available from: http://www.ctlscientific.com/pages/aquadur.html\#: :text= AQUADUR\%C2\%AE\%20test\%20strips\%20are,magnesium\% 20salts\%20within\%20the\%20water. Accessed Feb 2019

31. Technology CF (2015) CIMCOOL - Metalworking fluid controls. Technical Report No. J/N 96/37. 2015: CIMCOOL Technical Reports. Cimcool Fluid Technology, Cincinnati. http://www. cimcool.com/wp-content/uploads/tech-reports/newcntrl.pdf. Accessed May 2019

32. Easy ways to test your water. [cited 2018; Available from: https:// homewater $101 . c 0 m / a r t i c l e s /$ easy-ways-to-test-water. Accessed Dec 2019

33. Rave A, Joksch S (2012) Monitoring metalworking fluids. In: Astakhov VP, Joksch S (eds) Metalworking Fluids (MWF) for Cutting and Grinding: Fundamentals and Recent Advances. Woodhead Publishing Series in Metals and Surface Engineering, pp 317-337. https://doi.org/10.1533/9780857095305.317

34. Reduce your machining costs with metalworking fluid management - Part 2 of 2. 2018 [cited 2018; Available from: https://q8oilshub.co. uk/2018/05/09/reduce-your-machining-costs-with-metalworkingfluid-management-chapter-2-of-2/. Accessed Mar 2019

35. Rabenstein A, Koch T, Remesch M, Brinksmeier E, Kuever J (2009) Microbial degradation of water miscible metal working fluids. Int Biodeterior Biodegradation 63(8):1023-1029

36. (2019) Metalworking fluids 12/10/2019]; Available from: http:// www.hse.gov.uk/metalworking/index.htm. Accessed 12 Oct 2019

37. What are dipslides? [cited 2018; Available from: https://www. droptestkits.com/microbiology/what-are-dipslides/. Accessed Sept 2019

38. Canter N (2008) Development of guidelines for using and maintaining metalworking fluids. Society of Tribologists and Lubrication Engineers. https://www.stle.org/ItemDetail? iProductCode $=$ WP METALWORKING\&Category $=$ WHITEPAPER \&WebsiteKey $=\mathrm{a} 70334 \mathrm{df}-8659-42 \mathrm{fd}-\mathrm{a} 3 \mathrm{bd}-$ be406b5b83e5. Accessed Jan 2020

39. Selvaraju SB, Khan IUH, Yadav JS (2005) Biocidal activity of formaldehyde and nonformaldehyde biocides toward Mycobacterium immunogenum and Pseudomonas fluorescens in pure and mixed suspensions in synthetic metalworking fluid and saline. Appl Environ Microbiol 71(1):542-546

40. Merschbrook E (2002) Entwicklung eines kombinierten UV-Licht-/ Ultraschall-Entkeimungsgerätes für trübe bzw. undurchsichtige Prozeßflüssigkeiten. Ingenieurbüro Merschbrock, Rietberg

41. Buchal K (2002) Desinfektion und Konservierung industrieller. Kühlschmierstoffe durch Ultraschall. Dr. Dissertation. Universität Kiel

42. Stauffer E, Dolan JA, Newman R (2008) CHAPTER 8 - Gas chromatography and gas chromatography-mass spectrometry. In: Stauffer E, Dolan JA, Newman R (eds) Fire Debris Analysis. Academic Press, Burlington, pp 235-293 
43. Popov A, Khramenkov M (2019) Effect of hydraulic oil entering the cutting fluid on the tool life and roughness in turning of stainless steel. Manuf Technol J 19(4):664-667

44. Forbes ES (1970) The load-carrying action of organo-sulphur compounds - a review. Wear 15(2):87-96

45. Corporation N Lubricant additives - a practical guide. [cited 2019; Available from: https://www.machinerylubrication.com/Read/ 31107/oil-lubricant-additives. Accessed Sept 2020

46. Smith H (1998) Flowing Together [cited 2019; Available from: https://www.ctemag.com/news/articles/flowing-together. Accessed Sept 2020

47. Schulz J, Brinksmeier E, Meyer D (2013) On the interactions of additives in metalworking fluids with metal surfaces. Lubricants 1(4):75-94
48. Hoobler GL (1990) Coolant management: a users' introduction and guide to waste minimization. In: Waste minimization and wastewater treatment of metalworking fluids. Independent Lubricant Manufacturers Association, Alexandria. https://www.p2infohouse. org/ref/19/18256.pdf

49. Sluhan CA (1986) Considerations in the selection of coolants used in flexible machining cells Society of Manufacturing Engineers Technical Paper MS86-124. SME, Dearborn p 1-5. 25

Publisher's note Springer Nature remains neutral with regard to jurisdictional claims in published maps and institutional affiliations. 